\title{
The role of the Brazilian Tuberculosis Research Network in national and international efforts to eliminate tuberculosis
}

\author{
Afranio Kritski1,a, Margareth Pretti Dalcolmo ${ }^{2, b}$, Fernanda Carvalho Queiroz Mello ${ }^{3, c}$, \\ Anna Cristina Calçada Carvalho $0^{4, \mathrm{~d}}$, Denise Rossato Silva ${ }^{5, \mathrm{e}}$, \\ Martha Maria de Oliveira ${ }^{6, f}$, Julio Croda ${ }^{7,8,9}$
}

\section{GLOBAL STRATEGY TO ELIMINATE TUBERCULOSIS}

In 2015, tuberculosis ranked as the leading cause of death from an infectious disease, surpassing HIV/AIDS. ${ }^{(1)}$ In 2016, an estimated 10.4 million people developed tuberculosis and 1.7 million died from the disease, 5,000 people dying from it every day, including approximately 1,000 individuals with tuberculosis/HIV coinfection. ${ }^{(1)}$ In the past decade, the global tuberculosis community has engaged in activities to successfully attain the Millennium Development Goal target and other international targets for halting and reversing increases in tuberculosis incidence and mortality. ${ }^{(1)}$ However, despite the achievements made to date, the global incidence of tuberculosis is declining at a rate of only $1.5 \%$ per year, far from the $10 \%$ expected. ${ }^{(1)}$

In 2014, the World Health Organization (WHO) launched its End TB strategy, ${ }^{(2)}$ with the stated goal of ending the global tuberculosis epidemic by lowering its incidence to fewer than 10 new patients per 100,000 population per year. The End TB strategy, aligned with the Sustainable Development Goals (SDGs), focuses on reducing the number of tuberculosis deaths by $90 \%$ and lowering the incidence of the disease by $80 \%$, as well as ensuring that no families of tuberculosis patients are affected by catastrophic costs incurred from diagnosis and treatment, with the objective of meeting all of those goals by 2030 . To that end, the End TB strategy has three pillars that leverage the strategy and are critical to ending the global tuberculosis epidemic: integrated patient-centered care and prevention; bold policies and supportive systems, with an emphasis on social protection of vulnerable populations; and intensified research and innovation. The third pillar (intensified research and innovation) promotes the need for research along a continuum that links upstream fundamental research to discovery, to new tool development, and ultimately to operational/implementation/health system research, allowing innovative strategic approaches to be adapted to country-specific needs. In 2015, the WHO Global
TB Program developed a global action framework for tuberculosis research, ${ }^{(3)}$ the objective of which was to foster cutting-edge tuberculosis research to contribute to the elimination of the tuberculosis epidemic, at the national and international levels. A key output at the country level is to create a national tuberculosis research network, pursuing the development of a national tuberculosis research plan that could be integrated into larger national tuberculosis control efforts. To assist countries, the WHO Global TB Program has developed a toolkit ${ }^{(4)}$ for defining and incorporating national tuberculosis research plans that target country-specific needs and resources that will help eliminate the global tuberculosis burden. By 2015, national tuberculosis research plans had been established in several high- and medium-burden countries, including Brazil, Ethiopia, Indonesia, Russia, South Africa, and Vietnam, all of which agreed to serve as pathfinder countries. ${ }^{(5)}$

In January of 2017, taking into account the fact that the actions carried out at the global level were failing to meet the milestones set in the End TB strategy, given the benefits gained per dollar spent on those actions, the United Nations General Assembly announced the first-ever high-level meeting on the fight against tuberculosis, to be held in 2018. ${ }^{(6)}$ In addition, the WHO and the Russian Federation decided to hold the first WHO Global Ministerial Conference on Ending TB (November 16-17, 2017) to promote action and commitments. ${ }^{(6)}$ Brazil, Russia, India, China, and South Africa, collectively known as the BRICS countries, bear $49 \%$ of the worldwide burden of tuberculosis and more than $60 \%$ of the multidrug-resistant tuberculosis burden. ${ }^{(1,7)}$ The BRICS national tuberculosis program managers and academic leaders established the BRICS TB Research Network in September of 2017, at a meeting held in the city of Rio de Janeiro, Brazil, where all of the BRICS countries made commitments to combating tuberculosis and to developing a tuberculosis research agenda. ${ }^{(8)}$

At the WHO Global Ministerial Conference on Ending TB, in November of 2017, the Moscow Declaration to End TB

\footnotetext{
1. Programa Acadêmico de Tuberculose, Faculdade de Medicina, Universidade Federal do Rio de Janeiro - UFRJ - Rio de Janeiro (RJ) Brasil.

2. Centro de Referência Hélio Fraga, Escola Nacional de Saúde Pública Sergio Arouca, Fundação Oswaldo Cruz, Rio de Janeiro (RJ) Brasil.

3. Instituto de Doenças do Tórax - IDT - Faculdade de Medicina, Universidade Federal do Rio de Janeiro, Rio de Janeiro (RJ) Brasil.

4. Laboratório de Inovações em Terapias, Ensino e Bioprodutos - LITEB - Instituto Oswaldo Cruz, Fundação Oswaldo Cruz, Rio de Janeiro (RJ) Brasil.

5. Faculdade de Medicina, Universidade Federal do Rio Grande do Sul - UFRGS - Porto Alegre (RS) Brasil.

6. Centro de Desenvolvimento Tecnológico em Saúde, Fundação Oswaldo Cruz, Rio de Janeiro (RJ) Brasil.

7. Faculdade de Medicina, Universidade Federal do Mato Grosso do Sul - UFMS - Campo Grande (MS) Brasil.

8. Fundação Oswaldo Cruz, Campo Grande (MS) Brasil.

a. (ID) http://orcid.org/0000-0002-5900-6007; b. (iD) http://orcid.org/0000-0002-6820-1082; c. (iD) http://orcid.org/0000-0003-3250-6738;

d. (iD) http://orcid.org/0000-0002-0128-942X; e. (iD) http://orcid.org/0000-0003-0230-2734; f. (iD) http://orcid.org/0000-0002-0064-387X

g. (iD http://orcid.org/0000-0002-6665-6825
} 
was approved. ${ }^{(9)}$ The declaration focused on the following essential building blocks, aimed at achieving revolutionary commitments for 2018 and beyond: advancing the tuberculosis response within the SDG agenda; ensuring sufficient and sustainable financing; pursuing science, research, and innovation; and developing a multisectoral accountability framework. The participants agreed to prepare and follow up on the United Nations General Assembly High-Level Meeting on Tuberculosis in 2018.

\section{BRAZILIAN TUBERCULOSIS RESEARCH NETWORK}

The Rede Brasileira de Pesquisas em Tuberculose (REDE-TB, Brazilian Tuberculosis Research Network) was created by an interdisciplinary group of Brazilian researchers with the common goal of promoting interaction among government, academia, health service providers, civil society, and industry on the development and implementation of new technologies and strategies to improve tuberculosis control throughout the country. ${ }^{(10)}$ At this writing, the REDE-TB had 320 members working at 65 institutions across 16 of the 27 Federal Units of Brazil (comprising 26 states and the Federal District of Brasília). When the REDE-TB was created, in 2001, it already comprised researchers from different regions of the country, who carried out investigations along a continuum that linked upstream fundamental research to discovery and new tool development, as well as to operational/ implementation, epidemiology, and health system research. The innovation consisted of strategies to achieve the following objectives:

a) to identify leaders in different areas/disciplines who were willing to coordinate connecting points (coordination areas), with a view to acting on different research platforms, upon which each subject can act on and champion processes whose key mission is to control tuberculosis

b) to identify gaps and partnerships, as well as to facilitate actions at the national, state (or provincial), and municipal levels

c) to focus on the ability of researchers and organizations to promote internal innovations in parallel with the incorporation of externally produced scientific and technological knowledge

d) to promote development and innovation in health, which should result not only from the important inputs to the health system, such as drugs/ medications, vaccines, diagnostic reagents, and equipment, but also from concepts and innovative practices to improve health, equity, and public health care systems

Over the last 16 years, the REDE-TB coordinators have endeavored to attain several goals and have been working closely with the National Tuberculosis Program (Brazilian Ministry of Health).

\section{THE ROLE OF THE REDE-TB IN IMPLEMENTING THE WHO END TB STRATEGY AT THE GLOBAL LEVEL}

In 2009, the WHO invited the REDE-TB to join the Global Task Force TB Research Movement. ${ }^{(11)}$ In 2006, the WHO reintroduced research as a recommended global tuberculosis control tool. ${ }^{(12)}$ However, research was not incorporated into tuberculosis control programs in high-burden countries. The REDE-TB has taken an active part in the ongoing debates among key stakeholders and has contributed to the development of the first WHO document related to operational research. ${ }^{(13)}$ In November of 2014, after research had been established as one of the three pillars in the WHO End TB strategy, Global TB Research Task Force debates prompted the WHO to hold up the REDE-TB platform as an example of how to establish links among the National Tuberculosis Program, researchers, the public health care system, the industrial sector, and civil society, in order to prioritize and conduct studies of strategic importance at the national level.

In June of 2015, the REDE-TB participated in the development of Global Action Framework for TB

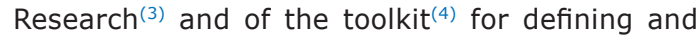
incorporating a national tuberculosis research plan targeting country-specific needs. In addition, because the REDE-TB and the National Tuberculosis Program (Brazilian Ministry of Health) launched the National Tuberculosis Research Agenda, Brazil was invited to serve as a pathfinder country to incorporate the third pillar of the WHO End TB strategy. In December of 2015, the REDE-TB, in collaboration with the National Tuberculosis Program (Brazilian Ministry of Health) and the Oswaldo Cruz Foundation, organized the first Brazil-China workshop on tuberculosis research, in the city of Rio de Janeiro, initiating the interaction on tuberculosis research among BRICS countries, focusing on the WHO End TB strategy. In October of 2016, the REDE-TB and National Tuberculosis Program (Brazilian Ministry of Health) entered into discussions with other BRICS countries on how to improve their collaborations to leverage the third pillar of the WHO End TB strategy. In June of 2017, the REDE-TB, the National Tuberculosis Program (Brazilian Ministry of Health) and the WHO Global TB Program held a meeting in Geneva, Switzerland, involving representatives of other national tuberculosis programs and of academia from BRICS countries, ${ }^{(14)}$ in order to identify the next steps in the creation of a BRICS TB Research Network. In September of 2017, the REDE-TB, representing academia, participated in the first meeting of the BRICS TB Research Network, held in the city of Rio de Janeiro. The meeting established that network following the resolution passed in the 6th Meeting of BRICS Health Ministers, held in New Delhi, India, on December 16, 2016. At that meeting, a Term of Reference was created and the following objectives were categorized as priorities: identifying strategies to accelerate clinical and implementation research; promoting multisectoral collaboration to drive research in the context of the SDGs; and promoting efforts and opportunities for mobilizing funding for tuberculosis research at the international level.(15) In November of 2017, the REDE-TB participated in the second meeting of the BRICS TB Research Network, held in 
Moscow, Russia. At that meeting, the following topics were addressed: key representation in government, academia, the industrial sector, and civil society, to assist in the implementation of the BRICS TB Research Network; the most promising means of optimizing the interaction among the BRICS countries; and existing technologies, vaccine production capabilities, drugs, diagnostic tests, and innovative activities in health management among the BRICS countries. Also in November of 2017, the REDE-TB participated in the first BRICS Science and Technology Meeting, focusing on antimicrobial resistance, held in Moscow. At that meeting, the REDE-TB presented the BRICS proposal to cope with drug-resistant TB within the global antimicrobial resistance agenda.

\section{THE ROLE OF THE REDE-TB IN IMPLEMENTING THE END TB STRATEGY AT THE NATIONAL LEVEL}

In 2004, the REDE-TB helped the creation of the first non-governmental organization to combat tuberculosis in Rio de Janeiro and, in November of that year, played an active role in the creation of the Brazilian Partnership against TB, linked to the STOP TB Partnership. To this day, the REDE-TB continues to be the academic representative to the Executive Committee of the Brazilian Partnership against TB. ${ }^{(10,16)}$ In addition, REDE-TB researchers led more than $80 \%$ of the tuberculosis research projects conducted in Brazil in the last decade. ${ }^{(17)}$

Since 2007, under new National Tuberculosis Program (Brazilian Ministry of Health) management, a higher level of interaction in research has taken place between the REDE-TB and the Brazilian government. Representatives of the REDE-TB came to participate in the National Technical Advisory Committee of the National Tuberculosis Program (Brazilian Ministry of Health). In 2007, the REDE-TB joined the Executive Secretariat of the Global Fund to Fight AIDS, Tuberculosis, and Malaria and helped the creation of the concept of metropolitan councils to combat tuberculosis.

In 2013, in response to a request by the WHO, the Global Task Force for TB Research, the REDE-TB, the Brazilian National Tuberculosis Program, and the Department of Science and Technology (Brazilian Ministry of Health) created the first national roadmap for tuberculosis research, at a meeting held in the city of São Paulo. The most relevant areas of tuberculosis research in Brazil were identified in order to develop the National Tuberculosis Research Agenda to comply with the third pillar of the WHO End TB strategy, which was under discussion at the WHO at that time. Also in 2013, the U.S. National Institute of Allergy and Infectious Diseases (of the National Institutes of Health) requested the help of the REDE-TB in identifying clinical sites in Brazil to carry out cohorts of tuberculosis cases and their close contacts, as part of the international Regional Prospective Observational Research in Tuberculosis (RePORT) project. The aim of the RePORT project, undertaken in partnership with India, South Africa, and China, was to collect clinical and biochemical data for later use in studies related to basic and translational research. Sites in the cities of Rio de Janeiro, Manaus, and Salvador have initiated the RePORT project with joint funding from the National Institute of Allergy and Infectious Diseases and the NMH Department of Science and Technology/ Department of Science, Technology, and Strategic Resources. Subsequently, a number of multi-country projects have been launched under the auspices of the RePORT International project, which represents a consortium of regional cohorts. ${ }^{(18)}$

In late 2015, the REDE-TB, in collaboration with the $\mathrm{MoH}-$ National Tuberculosis Program (Brazilian Ministry of Health) and the Oswaldo Cruz Foundation, consolidated the National Tuberculosis Research Agenda, to be adopted by public policy makers and funding bodies. ${ }^{(19)}$ The research priorities were developed through the use of multiple research platforms (covering the spectrum from basic science to health system research). In 2016, the REDE-TB and the National Tuberculosis Program (Brazilian Ministry of Health) carried out a national electronic survey to review the National Tuberculosis Research Agenda. Of the 73 research priorities identified in the National Tuberculosis Research Agenda, 21 were selected ( 3 from each of the seven research platforms). ${ }^{(20)}$ In that same year, the REDE-TB presented a preliminary national tuberculosis research plan at a public hearing at the Brazilian National House of Representatives, where the creation of the BRICS TB Research Network was discussed. ${ }^{(21)}$ Also in 2016, the REDE-TB submitted a preliminary national tuberculosis research plan (including a budget for the 2017-2021 period) to the National Tuberculosis Program (Brazilian Ministry of Health) and the Brazilian Ministry of Science and Technology. ${ }^{(22)}$.

In 2017, a research agenda for social protection was defined at the first Workshop on Research in Social Protection for the Control of Tuberculosis, held in the city of Brasilia. The REDE-TB, together with the WHO Global TB Program, the National Tuberculosis Program (Brazilian Ministry of Health), and the Faculty of Epidemiology and Population Health at London School of Hygiene and Tropical Medicine, has discussed the national research proposal to cover the following topics: identifying determinants of tuberculosis patient access to social protection in Brazil, at the structural and individual level; investigating how different models of health care delivery can increase access to social protection and treatment for tuberculosis patients and their families; and establishing a platform to link biomedical and social protection research. (23) The REDE-TB was invited to participate in the development of the Brazilian National Plan for Eliminating Tuberculosis, which focuses on a number of principles, challenges, and objectives:

a) For the Sistema Único de Saúde (SUS, Brazilian Unified Health Care System) and the Brazilian National Health Council, the priority is to provide 
quality care, with little involvement in the development of domestic products (medicines, vaccines, and diagnostic tests).

b) Few professionals coming out of universities are available to work within the national health industry.

c) Leaders in academia and researchers in the health arena are averse to interacting with industry.

d) There are difficulties with the regulatory system of Brazil (e.g., the National Research Ethics Committee and the National Health Oversight Agency) in launching and carrying out national projects in collaboration with international organizations.

e) Academia and the public health care system have not prioritized quality system management, few public clinical facilities and laboratories having been certified by the Brazilian National Institute of Metrology.

f) There is a high (12-billion-dollar) annual trade deficit in the health sector, due to low international competitiveness and limited national private sector investment in biotechnology.

In June 2017, during the 15th National Exposition of Successful Experiences in the Epidemiology, Prevention, and Control of Diseases meeting, held in Brasília, the National Plan for Eliminating Tuberculosis was launched. The REDE-TB coordinators actively organized the various stages, such as public consultations and meetings, in the development of the plan proposed by the Brazilian Ministry of Health. The National Plan for Eliminating Tuberculosis is based on the three pillars of the WHO End TB strategy, and the experience of the REDE-TB was used in order to foster interaction between the third pillar and the two other pillars. The established objective of the plan is the elimination of tuberculosis as a public health problem by 2035 , to be achieved in four phases, with intermediate milestones in 2020, 2025, and 2030. The plan also has the objective of extirpating catastrophic household expenditures resulting from the disease, by 2020. In addition, the reductions envisioned in the numbers of tuberculosis-related deaths are $35 \%, 75 \%$, and $90 \%$ by 2020,2025 , and 2030 , respectively, with corresponding reductions in the incidence of the disease of $20 \%, 50 \%$, and $80 \%$, respectively. In June of 2017, the REDE-TB was invited to represent academia at the first meeting of the Congressional Working Group of Representatives to monitor the National Plan for Eliminating Tuberculosis launched by the Brazilian Ministry of Health. ${ }^{(24)}$ In July of 2017, the REDE-TB and the National Tuberculosis Program (Brazilian Ministry of Health) organized the VI National Workshop on Tuberculosis Research, in the city of Rio de Janeiro. The main aims of the workshop were to promote the creation of a National Tuberculosis Research Committee, incorporating the third pillar of the WHO End TB strategy into the National Plan for Eliminating Tuberculosis; to optimize the implementation of the National Tuberculosis Research Agenda, facilitating its execution and monitoring; and to identify strategies that encourage key actors in tuberculosis research and tuberculosis program managers to participate in the inclusion of the third pillar of the WHO End TB strategy (research) and to interact effectively with those working on the first and second pillars. ${ }^{(25)}$ In July of 2017, the REDE-TB presented the National Tuberculosis Research Plan to the Brazilian National Health Council. ${ }^{(26)}$ In August of the same year, the REDE-TB and the National Tuberculosis Program (Brazilian Ministry of Health) helped the creation of the National Committee for Community-Based Monitoring of Tuberculosis, in order to foster interaction between researchers and civil society. In November of that year, in response to a request from the Congressional Working Group of Representatives to monitor the National Plan for Tuberculosis Elimination, the REDE-TB suggested the following actions, considered strategic for the implementation of the National Plan for Eliminating Tuberculosis:

a) the creation of a interministerial commission on science, technology, and innovation in tuberculosis to coordinate national efforts related to scientific and technological development and innovation, as well as to analyze the clinical, epidemiological, and budgetary impact of the incorporation of new technologies into the SUS

b) the development of public policies that facilitate interaction between the industrial sector and universities/research institutes, aimed at the development of new technologies, at the national level, and their validation in the health care system, in order to avoid the importation of technologies and decrease the trade deficit in the health sector

c) the promotion, together with government agencies, supported by the Parliamentary Front Against Tuberculosis in the Americas, the national health industry, and the BRICS TB Research Network, of the allocation of specific financial resources for tuberculosis research in areas related to the three pillars of the WHO End TB strategy, at the national and international levels

d) the building of capacity for research on tuberculosis within the health care system, fostering this research in undergraduate courses and graduate courses (master's and doctoral programs)

e) the development of innovative local information systems for epidemiological surveillance, enabling the registration, follow-up, and analysis of tuberculosis patients and their contacts, including the collection of basic information, as well as data on treatment, examinations, and hospitalizations

f) the active participation of universities and research institutes in the Brazilian National Tuberculosis Control Program, in the evaluation of new health technologies incorporated into the SUS, and in monitoring the goals and process indicators proposed in the National Plan for Tuberculosis Elimination, underscoring the need to conduct operational and implementation research, through quantitative and qualitative studies, on tuberculosis/ HIV coinfection, multidrug-resistant tuberculosis, tuberculosis among prisoners, and tuberculosis among homeless people, as well as tuberculosis associated with mental disorders, alcohol use, and the use of other drugs

g) the development of integrated research projects in the social protection and biomedical aspects 
of tuberculosis infection, taking human values into account

\section{FINAL REMARKS}

The REDE-TB represents a novel form of collaboration, in which the synergy of its complementary aspects facilitates the transfer of knowledge among academia, the government, civil society, and the national industrial sector to the community. A model that integrates and links efforts, using multisectoral approaches, has been used by the WHO to develop the third pillar of its End TB strategy and played a key role in the creation of the BRICS TB Research Network, as well as in encouraging the Brazilian Government to include tuberculosis in the national political health agenda.

\section{REFERENCES}

1. World Health Organization. Global tuberculosis report 2017. Geneva: WHO; 2017.

2. Uplekar M, Weil D, Lonnroth $K$, Jaramillo E, Lienhardt C, Dias HM, et al., WHO's new end TB strategy. Lancet. 2015;385(9979):17991801. https://doi.org/10.1016/S0140-6736(15)60570-0

3. World Health Organization [homepage on the Internet]. Geneva: World Health Organization; c2015 [cited 2017 Nov 24]. A global action framework for TB research in support of the third pillar of WHO's end TB strategy; [about 2 screens]. Available from: http:// www.who.int/tb/publications/global-framework-research/en/

4. World Health Organization [homepage on the Internet]. Geneva: World Health Organization; c2015 [cited 2017 Nov 24]. A Toolkit for Developing A National TB Research Plan, in support of the third pillar of the End TB Strategy; [about 2 screens]. Available from: http:// www.who.int/tb/publications/TB_research_toolkit/en/

5. World Health Organization [homepage on the Internet]. Geneva: WHO; c2016 [cited 2017 Nov 24]. Global Tuberculosis Report 2016 [about 2 screens]. Available in http://www.who.int/tb/publications/ global_report/en/

6. United Nations [homepage on the Internet]. New York (NY): United Nations [cited 2017 Nov 24]. Global health and foreign policy: health employment and economic growth. [about 9 screens]. Available from: http://www.un.org/en/ga/search/view_doc.asp?symbol=A/ RES/71/159

7. Lavrov S. BRICS: a new generation forum with a global reach. University of Toronto [article on the Internet]. 2016 Oct 20 [cited 2017 Nov 24]; BRICS Information Centre [about 3 screens]. Available from: http://www.brics.utoronto.ca/newsdesk/delhi/lavrov.html

8. Raviglione M, Uplekar M, Weil D, Kasaeva T. Tuberculosis makes it onto the international political agenda for health...finally. Lancet Glob Health. 2018;6(1):e20-e21. https://doi.org/10.1016/S2214109X(17)30449-7

9. World Health Organization [homepage on the Internet]. Geneva: WHO; c2016 [cited 2017 Nov 24]. Moscow Declaration to End TB [about 2 screens]. Available from: http://www.who.int/tb/features_ archive/Online_Consultation_MinisterialConferenceDeclaration/en/

10. Kritski A, Ruffino-Netto A, Trajman A, Villa TCS, Lapa e Silva JR, Haddad DJ, et al. Brazilian Tuberculosis Research Network - REDETB. An Inst Hig Med Trop. 2016;15(Suppl 1):S35-S44.

11. Lienhardt C, Espinal M, Pai M, Maher D, Raviglione MC. What research is needed to stop TB? Introducing the TB Research Movement. PLoS Med. 8(11): e1001135. https://doi.org/10.1371/ journal.pmed.1001135

12. World Health Organization. STOP TB Partnership. The Global Plan to Stop TB 2006-2015. Geneva: World Health Organization; 2006.

13. World Health Organization [homepage on the Internet]. Geneva: WHO; [cited 2017 Nov 24]. Priorities in Operational Research to Improve Tuberculosis Care and Control. [Adobe Acrobat document, 133p.]. Available from: http://www.stoptb.org/assets/documents/ resources/publications/technical/StopTB\%20Guide.pdf

14. REDE-TB [homepage on the Internet]. São Paulo: REDE-TB; [cited 2017 Nov 24]. Strategic Advisory Group and Technical for Tuberculosis (STAG-TB); [about 2 screens]. http://www.redetb. org/index.php/262-grupo-consultivo-estrategico-e-tecnico-para-atuberculose-stag-tb

15. REDE-TB [homepage on the Internet]. São Paulo: REDE-TB; [cited 2017 Nov 24]. Establishment of the Research Network on Tuberculosis, countries belonging to the BRICS: Brazil, Russia,
India, China and South Africa; [about 4 screens] Available from: http://www.redetb.org/index.php/296-estabelecimento-da-rede-depesquisa-em-tuberculose-dos-paises-pertencentes-ao-brics-brasilrussia-india-china-e-africa-do-sul

16. REDE-TB [homepage on the Internet]. São Paulo: REDE-TB; [cited 2017 Nov 24]. Brazilian Partnership Against Tuberculosis elects new coordination; about 3 screens]. Available from: http://www.redetb. org/index.php/299-parceria-brasileira-contra-a-tuberculose-elegenova-coordenacao

17. Vasconcellos AG, Morel CM. Enabling policy planning and innovation management through patent information and co-authorship network analyses: a study of tuberculosis in Brazil. PLoS One. 2012;7(10):e45569. https://doi.org/10.1371/journal.pone.0045569

18. Hamilton CD, Swaminathan S, Christopher DJ, Ellner J, Gupta A Sterling TR, et al. RePORT International: Advancing Tuberculosis Biomarker Research Through Global Collaboration. Clin Infect Dis. 2015;61Suppl 3:S155-9. https://doi.org/10.1093/cid/civ611

19. Kritski A, Barreira D, Junqueira-Kipnis AP, Moraes MO, Campos MM, Degrave WM, et al. Brazilian Response to Global End TB Strategy : The National Tuberculosis Research Agenda. Rev Soc Bras Med Trop. 2016;49(1):135-45. https://doi.org/10.1590/0037-8682-03302015

20. REDE-TB [homepage on the Internet]. São Paulo: REDE-TB; [cited 2017 Nov 24]. Linhas de Pesquisas em Tuberculose Priorizadas em 2016. [Adobe Acrobat document, 3p.]. Available from. http:// www.redetb.org/attachments/article/239/Linhas \%20Pesquisas $\% 20$ em\%20TB\%20Priorizadas\%20Dez\%202016.pdf

21. REDE-TB [homepage on the Internet]. São Paulo: REDE-TB [cited 2017 Nov 24]. Public hearing debate national plan to end tuberculosis; [about 3 screens]. Available from: http://www.redetb. org/index.php/238-audiencia-publica-debate-plano-nacional-pelo-fimda-tuberculose

22. REDE-TB [homepage on the Internet]. São Paulo: REDE-TB; [cited 2017 Nov 24]. National TB Research Plan-RedeTB Proposal-2016 Dec 16. [Adobe Acrobat document, 38p.]. Available from: http:// www.redetb.org/attachments/article/250/National\% 20TB\%20 Research \% 20Plan \% 20-Rede \% 20TB \% 20Proposal\% 20-\% 20 Dec\%2016\%20-\%202016.pdf

23. REDE-TB [homepage on the Internet]. São Paulo: REDE-TB; [cited 2017 Nov 24]. Research in social protection for tuberculosis control is international debate topic; [about 2 screens]. Available from: http:// www.redetb.org/index.php/253-pesquisa-em-protecao-social-paracontrole-da-tuberculose-e-tema-de-debate-internacional

24. REDE-TB [homepage on the Internet]. São Paulo: REDE-TB; [cited 2017 Nov 24]. Commission on Social Security and Family House of Representatives installs Working Group to monitor the National Plan For Tuberculosis End; [about 2 screens]. Available from: http:// www.redetb.org/index.php/259-comissao-de-seguridade-social-efamilia-da-camara-dos-deputados-instala-grupo-de-trabalho-para-oacompanhamento-do-plano-nacional-pelo-fim-da-tuberculose

25. REDE-TB [homepage on the Internet]. São Paulo: REDE-TB; [cited 2017 Nov 24]. VI Workshop Nacional da Rede TB. Rio de Janeiro, junho de 2017; [about 15 screens]. Available from: http://www. redetb.org/index.php/noticias/workshop-rede-tb-2017

26. REDE-TB [homepage on the Internet]. São Paulo: REDE-TB; [cited 2017 Nov 24]. CIASPP document presents strategies against Tuberculosis; [about 3 screens]. Available from: http://www.redetb. org/index.php/290-comissao-intersetorial-de-atencao-a-saude-depessoas-com-patologias-ciaspp-em 